\title{
Avulsion of the Hamstring Muscle Group: A Follow-Up of 6 Adult Non-Athletes with Early Operative Treatment: A Brief Report
}

\author{
Ladislav Mica · Adrian Schwaller • \\ Christoferos Stoupis · Igor Penka • \\ Jindřich Vomela $\cdot$ Andreas Vollenweider
}

Published online: 17 June 2009

(C) Société Internationale de Chirurgie 2009

\begin{abstract}
Background Complete proximal avulsions of the hamstring muscle group may cause significant morbidity and loss of function. These pelvis-near musculoskeletal injuries are mostly acquired during sports activities in a hip flexion and knee extension. Here we present a study group of 6 middle-aged to elderly patients suffering a complete proximal hamstring avulsion and following early surgical refixation. Early surgical refixation leads to complete resumption of the activities of daily life without loss of function.

Materials and methods The 6 patients $(3$ men and 3 women) included in this study had an average age of $59.07 \pm 4.47$ years at the time of injury. All of them suffered a complete avulsion of the hamstring muscle group. Surgical refixation was accomplished with the corkscrew anchor refixation system (Arthrex Manufacturing, Inc., Naples, FL). The cases were retrospectively analyzed using a hip joint evaluation system, the Harris Hip Score, and radiological follow-up by magnetic resonance imaging
\end{abstract}

L. Mica $(\bowtie)$

Department of Trauma Surgery, University Hospital of Zürich, Rämistrasse 100, 8091 Zürich, Switzerland

e-mail: ladislav.mica@usz.ch

L. Mica $\cdot$ A. Schwaller $\cdot$ A. Vollenweider Department of General Surgery, Spital Männedorf, Männedorf 8708 , Switzerland

C. Stoupis

Department of Diagnostic Radiology, Spital Männedorf, Männedorf 8708, Switzerland

I. Penka $\cdot$ J. Vomela

Department of Surgery, University Hospital of Brno,

62500 Brno, Czech Republic
(MRI). Data are given as mean \pm SEM. Student's $t$-test was used for normal distribution of the data.

Results The mean follow-up time was $31.83 \pm 18.9$ months (range: 10-118 months). All patients were rated not to have a significant difference in function compared with the uninjured side. None of the patients suffered any handicaps resulting from surgery or the injury. A complete consolidation in all patients was observed in the follow-up MRI.

Conclusions Early surgical intervention and subsequent therapy in a complete hamstring avulsion injury may prevent loss of hip-joint stability and prevent the sequalae of degradative hip or vertebral events.

\section{Introduction}

Hamstring injuries occur during sporting activities such as maximal sprinting and hurdle running [1-3]. The patients often feel a subgluteal pain accompanied with an audible snap. Most hamstring injuries can be managed conservatively if there is only partial rupture of the tendons [4], but most are also prone to high recurrence rates [5]. In other types of hamstring injuries surgery is clearly recommended [6-9]. The surgical treatment of hamstring injuries and the outcome of those surgical procedures have received relatively little attention [10-12]. The muscle group of the hamstrings consists of three muscles: the biceps femoris, the semimembranosus, and the semitendinosus. The distal insertion side of the biceps femoris is the proximal lateral tibia head and the head of the fibula, the distal insertion side of the semimembranosus muscle is the mediodorsal proximal tibia head. The biceps femoris together with the semimembranosus muscle form the popliteal arcade. The 
distal insertion side of the semitendinosus muscle is the anteromedial tibial head; the semitendinosus, with the sartorius and the gracilis muscles, forms the pes anserinus. The proximal insertion side of these three muscles is the ischial tuberosity. The mostly injured muscle of this group is the biceps femoris, and the injury usually occurs at the muscle tendon junction side $[13,14]$ in young sportive patients. Most avulsions are treated nonoperatively, with operative treatment suggested if the diastasis of the rupture cleft is more than $2 \mathrm{~cm} \mathrm{[15].}$

Sociostructural changes in Western societies has led to changes in the individual activities of the citizens. Aging and increasing sportive activities of people over the age of 60 years can lead to age- and sports-specific injuries. Thus the hamstring injury formerly reserved for athletes and young sportive adults may occur in middle-aged to elderly patients. In our study we present 6 such patients with complete hamstring avulsion who underwent operation for refixation. The follow-up of the early surgical treatment revealed not only very good integration into everyday activities but also a good sportive age-related integration.

\section{Methods}

Six patients with complete avulsion of the hamstring muscle group were treated in our department between the years 1999-2008. In all cases avulsion of the biceps femoris, semitendinosus, and semimembranosus muscles was complete. The cases were reviewed retrospectively. None of the patients had to be excluded for concomitant pelvis-near injuries, which would have required a different therapy and follow-up. After operative treatment the follow-up periods for our 6 patients were 6 weeks, 3 months, 6 months, and 12 months or more. The male to female ratio of the patients was 1:1 ( 3 women and 3 men). The mean age was $59.07 \pm 4.45$ years at the date of the surgical refixation (mean \pm SEM; range: 73.42-47.33 years). In 4 of the patients the injury was on the left side; in the other 2, on the right side. All patients were included according to the standards and with the agreement of the hospital ethics committee.

Trauma mechanism and initial diagnostics

All patients suffered a hyperflexion trauma in the hip, mostly combined with an extension in the knee on the same side during everyday activities. Walking downstairs and missing the last step was described by these patients, and this leads to unexpected hyperextension of the knee and compensatory flexion of the hip. This combination leads to acquisition of a hamstring injury. Gardening, a frequent activity of the middle-aged to elderly patient, often leads to the same injury caused by steps or uneven ground. Recreational sporting activities such as walking, hiking, and cycling were reported by the patients as regular activities. None of the patients were high-level athletes. No acoustic effect at the trauma event was registered in any of the included patients. The first clinical finding was pain. After a brief delay the patients presented in the emergency department (delay: 12-48 h) because of persistent pain and weakness affecting stability of the hip during walking. Clinical examination revealed a painful infragluteal rim, usually with an infragluteal hematoma in statu nascendi and relaxed hamstrings compared to the uninjured side. Palpation of the ischial tuberosity was inconclusive; in fact,
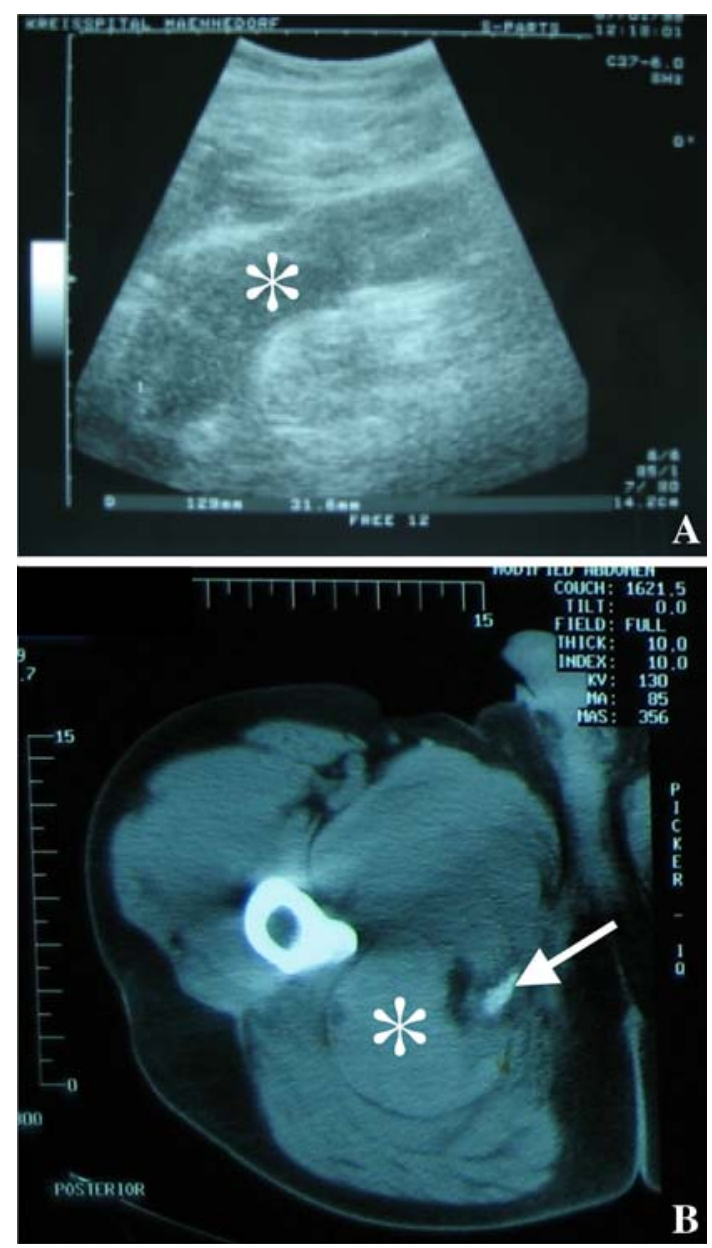

Fig. 1 Initial diagnostic findings in a 48-year-old man with avulsion of the hamstring muscle group and initial ischial palsy caused by a huge hematoma in the posterior compartment of the right limb. a Conventional sonographic examination shows a collection of liquid (asterisk) $(3 \times 13 \mathrm{~cm})$. b. Computer tomographic (CT) scan of the proximal femoral region shows a hematoma (asterisk) with a small bone chip originating from the ischial tuberosity (arrow). Emergent evacuation of the hematoma and refixation of the hamstring components led to complete remission of the ischial palsy. In this emergent case no initial magnetic resonance imaging (MRI) scans were obtained to assure the diagnosis 
it was often impossible because of the infraglueteal hematoma. Sonographically there was a high suspicion of tendomuscular injury of the hamstring muscle group (Fig. 1a). In one case, an emergency CT scan of the caudal pelvis because of ischial palsy revealed an infragluteal hematoma, with a hematoma in the hamstring compartment and an osseous fragment dislocated from the ischial tuberosity (Fig. 1b) (In this case no initial MRI was obtained because the initial diagnosis led to emergency operation). To confirm the suspicion of complete avulsion of the hamstring muscle group MRI $(n=5)$ was obtained to confirm the initial diagnosis (Fig. 2a and 2b). One of the included patients developed ischial palsy with a sensorimotor deficit, completely resolving after emergency evacuation of the hematoma and reinsertion of the hamstring muscle group.

\section{Surgical procedure}

All patients were positioned in a prone position on the operating table with their arms adducted. The initial approach was transverse in the infragluteal rim. After dissection of the subcutaneous fatty tissue, the surgeon took the direct approach into the posterior hamstring compartment identifying the torn hamstring muscle group. The only critical structure requiring protection is the ischial nerve, which is positioned laterally. Both muscle stumps are identified and the tuberal ischii are prepared for reinsertion. In treating a pelvis (bone)-near avulsion of a tendon, a corkscrew anchor system (titanium; Arthrex Manufacturing) was used. Usually three corkscrews were applied into the ischial tuberosity and the tendon was reinserted with an interweaving suture technique (Fig. 3a and $3 \mathrm{~b}$ ). A medium-sized drain was placed, and its removal was based on the secretion fluid measured $24-48 \mathrm{~h}$ postoperation.

Physiotherapeutic treatment and follow-up

Postoperatively the patient was mobilized on crutches with $15 \mathrm{~kg}$ weight bearing on the affected side after removal of the drain. Hip flexion over $30^{\circ}$ was avoided, as was forced extension over $30^{\circ}$ in flexion of the knee. An extension high-seat was used for the toilet, and other sitting activities had to be avoided. All patients received oral anticoagulants to avoid deep venous thrombosis for the first postoperative
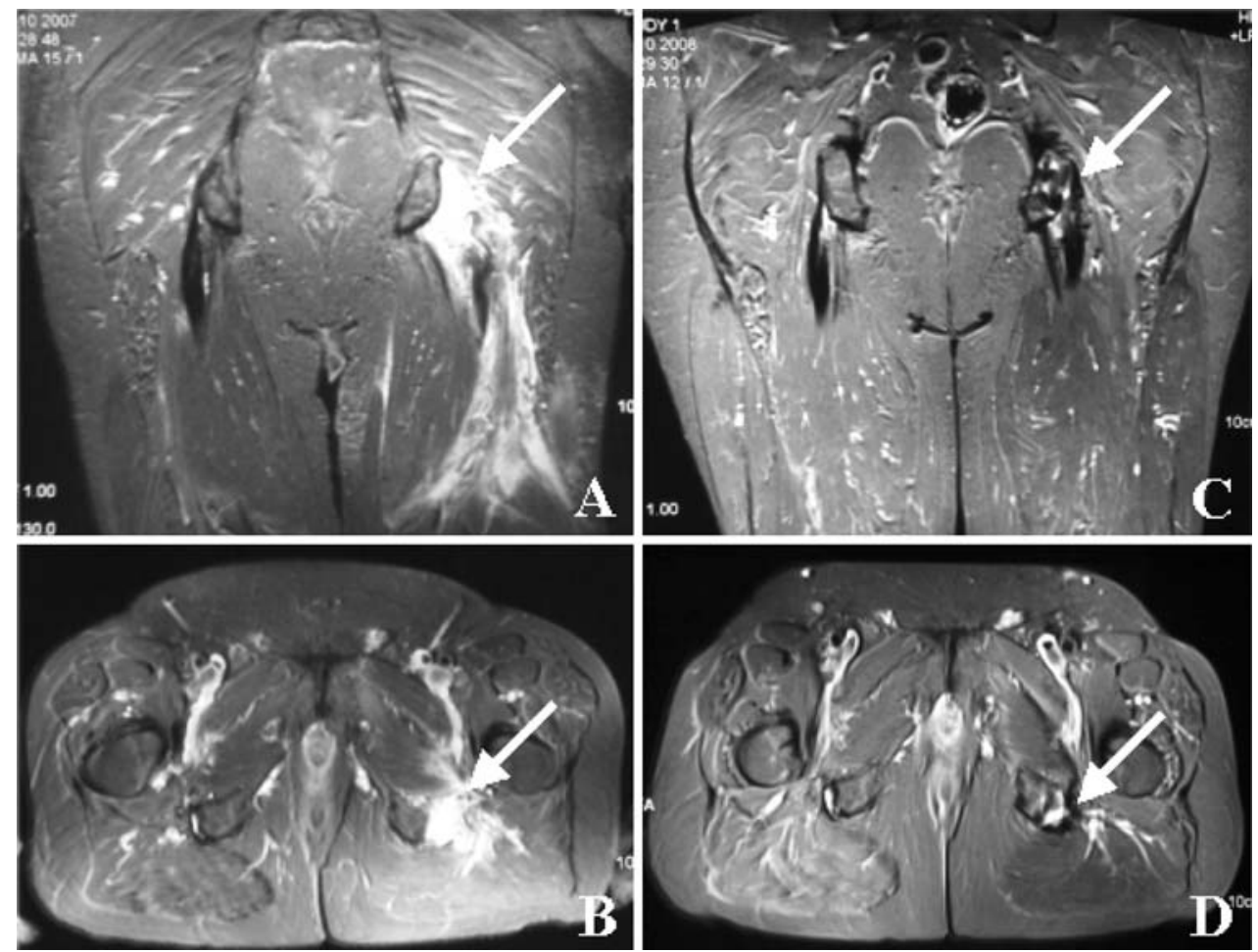

Fig. 2 a Coronal inversion recovery (IR) fat-saturated MRI of the hamstring tendons demonstrates edema (high signal intensity) around the tendon and muscles, with avulsion of the left hamstring tendon origin (arrow). Compare the findings with the right side. b A similar scan in the transverse plane reveals hemorrhage and avulsion of the left proximal common hamstring tendon (arrow). c and d The same

planes and the same MRI parameters in the same patient after surgical repair (12 months) of the hamstring tendon injury. The sequence allows a good overview of the adapted conjoined tendon (arrows) and the surgical sutures (corkscrew anchor system; black intraosseous spots) as compared to the right, normal side. No fatty muscular degeneration was observed after operative treatment 


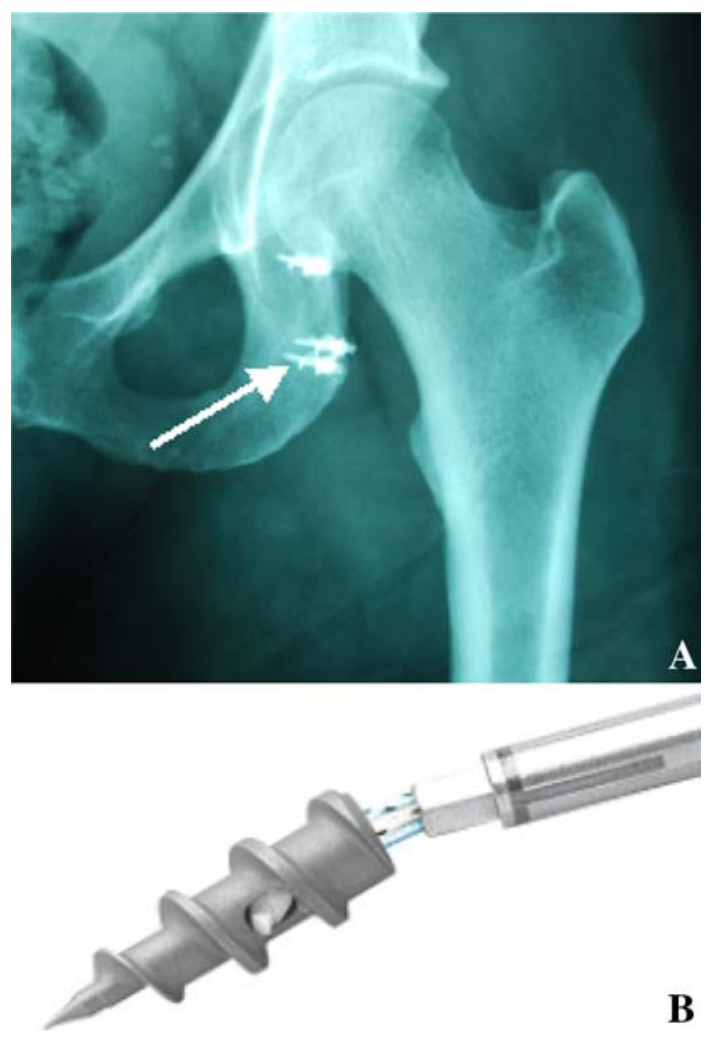

Fig. 3 a Conventional radiologic imaging after reinsertion of the hamstring muscle group after avulsion injury. The corkscrew anchors are located in the ischial tuberosity (arrow). An interwoven suturing technique was employed to approximate the tendons to the rupture site after application of the corkscrew anchoring system. b With the corkscrew anchor system from Arthrex Manufacturing, small conical screws can be applied into spongiform bone for reattachment of soft tissue structures. (Illustration kindly provided by Arthrex Manufacturing, Inc., Naples, FL.)

6 weeks. Conventional nonsteroidal anti-inflammatory drugs (NSAR/NSAID) were used to manage postoperative pain. After 6 weeks the patients were advised to restart mobilization with full weight-bearing, and to avoid sports for an additional 6 weeks. After the 12-week recovery period, patients were able to resume full physical activity and were reintegrated into normal daily routines. To assess functionality, we used the Harris hip score [16] as modified according to Haddad et al. [17] considering the hip to be a musculoskeletal functional unit. At the final follow-up visit, MRI $(n=6)$ was used to asses the repair, with a fat saturated MR protocol (TI $130.0 \mathrm{~ms}$; TR $5000.0 \mathrm{~ms}$; TE $28.0 \mathrm{~ms}$; TA 03:45 ms; BW $130.0 \mathrm{~ms}$ ).

\section{Statistical analysis}

Data, given as mean \pm SEM, were considered as statistically significant if $p<0.05$. For normal distribution of the data, Student's $t$-test was used. Statistical analysis was performed using SigmaStat for Windows 3.00.

\section{Results}

Clinical findings of the patients and final follow-up

The mean follow-up after surgical proximal reinsertion of the hamstring muscle group was $31.83 \pm 18.9$ months (range: 10-118 months). There was no significant differences between the women and the men in terms of age ( $p=0.927 ; n=3$ each group) or the time of final followup ( $p=0.368 ; n=3$ each group) (Table 1$)$.

The examinator's first impression was symmetrical walking. The skin was intact and without pain manifestation. Palpation of the ischial tuberosity showed a symmetrical tendinous strain without manifestation of pain. For evaluation of the function of the injured side we used the Harris hip score. No significant differences were found between the anamnestically evaluated Harris hip score before the trauma and the value at the final follow-up. There were no significant differences between the injured and non-injured sides at the final follow-up (Table 1). The patients were able to resume the activities of daily life by the time of the final follow-up.

\section{Final radiological evaluation}

To asses the operative success of the reinsertion of the hamstrings, a final MRI examination was performed. The specific scanning sequence allowed a good overview of the conjoined tendon and the surgical sutures as opposed to the uninjured side. No fatty muscular degeneration was observed after operative treatment (Fig. 2c and 2d). There was no signal alteration at the bone-tendon border or in the tendons compared to the uninjured side (Fig. 2c and 2d), and the hematoma was resolved. A radiologist experienced in interpretation of MRI scans considered the tendons to be healed in every case.

\section{Discussion}

Injury to the hamstring was traditionally described in athletic individuals occurring in non-contact situations while the person was running [2, 18, 19]. With our study group we presented an unusual patient population of middle age or older. In the industrialized and Western-oriented societies aging of the population does not represent a particular problem, but shifts in sporting activities with age will likely lead to injury in older populations. Furthermore, hamstring injuries are not only connected only with sporting activities but also with everyday activities in middle-aged to elderly patients. A "bad movement" in a middle-aged to elderly untrained patient can lead to a tear of the hamstrings. The mechanism is similar to that seen in 
Table 1 Overall distribution of the 6 patients ( 3 men and 3 women) included in this study

\begin{tabular}{|c|c|c|c|c|c|}
\hline Age, years & Sex & $\begin{array}{l}\text { Follow-up, } \\
\text { months }^{\mathrm{a}}\end{array}$ & $\begin{array}{l}\text { Delay to surgery, } \\
\text { days }\end{array}$ & Initial complications $^{\mathrm{b}}$ & $\begin{array}{l}\text { Harris hip score, } \\
\text { left/right }^{\mathrm{c}}\end{array}$ \\
\hline 65.58 & M & 10 & 4 & $\begin{array}{l}\text { Inability to run } \\
\text { Painful walking }\end{array}$ & $100 / 100$ \\
\hline 61.67 & M & 20 & 28 & $\begin{array}{l}\text { Inability to run } \\
\text { Painful walking }\end{array}$ & $100 / 100$ \\
\hline 73.42 & $\mathrm{~F}$ & 19 & 5 & $\begin{array}{l}\text { Inability to run } \\
\text { Painful walking }\end{array}$ & $86 / 86$ \\
\hline 57.42 & $\mathrm{~F}$ & 12 & 3 & $\begin{array}{l}\text { Inability to run } \\
\text { Painful walking }\end{array}$ & $100 / 100$ \\
\hline 47.33 & $\mathrm{~F}$ & 12 & 7 & $\begin{array}{l}\text { Inability to run } \\
\text { Painful walking }\end{array}$ & $97 / 97$ \\
\hline 48.21 & M & 118 & 2 & $\begin{array}{l}\text { Initial palsy of ischial nerve } \\
\text { Inability to run } \\
\text { Painful walking }\end{array}$ & $100 / 100$ \\
\hline
\end{tabular}

${ }^{a}$ The final follow-up was conducted 10-118 months after surgical reinsertion of the hamstring muscle group

${ }^{\mathrm{b}}$ Pain and a certain weakness of the involved hip were observed, and one patient developed increasing ischial palsy with a sensorimotor deficit that resolved after surgical intervention.

${ }^{c}$ Harris hip score was determined at the final follow-up visit of each patient, and no differences between injured and not injured side, and compared to the injured side before trauma. (Harris hip score maximum 100 points; a good result was a rating over 75 points)

younger patients: hyperflexion in the hip and extension in the knee. Epidemiological studies have shown that lesions of the hamstring muscle group occur during eccentric contractions [18, 20, 21]. The microscopic working hypothesis seems to posit a non-uniform lengthening of the sarcomeres resulting in microscopic damage [18, 22, 23]. With chronic repetition of these eccentric contractions, a locus minoris resistentiae may develop, leading to an avulsion injury if the appropriate mechanism occurs. Various mechanisms of action of the hamstrings have been described in young athletic individuals, and the multifunctionality of this muscle group seems to be the basis for its susceptibility to injury: Eccentric contraction and slowing knee extension, as well as isometric contraction to control pivoting of the knee and to take part in extension of the hip, are functions that may take place almost simultaneously, resulting in damaged sarcomeres [22, 23]. Neurologically, the M. biceps femoris is bineurally controlled, indicating a possibility of mistimed neurological control. Mistiming of the innervations may lead to reduced effective force and failure to fulfill the mechanical movement [18]. To understand the mechanism of avulsion, we have also to infer the mismatch of forces between M. quadriceps femoris and the hamstrings as its counter-players. Weak hamstrings may be susceptible to injury. A consensus suggests that healthy hamstring muscles have to be able to develop $>60 \%$ of the force of the M. quadriceps femoris $[24,25]$. In middle-aged to elderly men and women certainly the same mechanisms contribute to avulsion injuries, which occur more acutely than chronically. Personal overestimation of one's fitness and strength may lead to acute hamstring avulsions. The clinical findings are the same as in young individuals: infragluteal hematoma, asymmetrical walking, and an inability to run. The physician's efforts to palpate a tendinous gap may be impeded by a hematoma along the infragluteal rim. Concomitant secondary injuries are rare. One patient with initial ischial palsy upon proximal avulsion of the hamstrings has to be mentioned. Even though rare, concomitant ischial palsy may occur and masquerade as lumbovertebral pathology $[26,27]$. In the single case in our group this problem completely resolved after surgical treatment and evacuation of the hematoma. Initial suspicion of a proximal avulsion of the hamstrings has to be confirmed. Initially, sonography was used as the initial diagnostic tool, and if there was significant evidence of an avulsion of the hamstrings, that diagnosis was confirmed by MRI. Unfortunately, there is not a report of a group of patients with torn hamstring tendons who were treated conservatively. Therefore, the operative treatment of this type of injury as a standard treatment cannot be assessed.

There is some evidence that fatty degradation of the muscle occurs in chronic hamstring lesions [28].

Nonoperative treatment of proximal hamstring avulsion has a poor prognosis, and although surgery seems to be recommended more frequently it is not yet a standard [9, 28]. In the group presented here, all patients were treated early, with a maximal delay to surgery of 28 days. To refix 
tendinous avulsion injuries, we used the corkscrew anchor system developed by Arthrex Manufacturing. The intraosseous application allows optimal adaptation to the ischial tuberosity. In addition, 6 weeks seems to be an appropriate period of time to mobilization, although the reported period has varied between 2 and 8 weeks [7-9, 28-31]. The outcome of the operative treatment revealed patients who had resumed the activities of daily living without any loss of functionality.

In conclusion, early operative treatment of hamstring avulsion in the middle-aged to elderly active patient seems to be recommended. Certainly the indication for the operative treatment has to be evaluated with respect to any concomitant diseases and the patient's capacity to recover and resume the activities of normal daily living.

\section{References}

1. Bennell KL, Crossley K (1996) Musculoskeletal injuries in track and field: incidence, distribution and risk factors. Aust J Sci Med Sport 28:69-75

2. Woods C, Hawkins RD, Maltby S et al (2004) The Football Association Medical Research Programme: an audit of injuries in professional football-analysis of hamstring injuries. Br J Sports Med 38:36-41

3. Orchard J, Seward H (2002) Epidemiology of injuries in the Australian Football League, seasons 1997-2000. Br J Sports Med 36:39-45

4. Kujala UH, Orava S, Jarvinen M (1997) Hamstring injuries. Current trends in treatment and prevention. Sports Med Arth Rev 23:397-404

5. Orchard JW (1998) Recurrent hamstring injury in Australian football. Med Sci Sports Exerc 30:S52

6. Alioto RJ, Browne JE, Barnthouse CD et al (1997) Complete rupture of the distal semimembranosus complex in a professional athlete. Clin Orthop Relat Res 336:162-165

7. Brucker PU, Imhoff AB (2005) Functional assessment after acute and chronic complete ruptures of the proximal hamstring tendons. Knee Surg Sports Traumatol Arthrosc 13:411-418

8. Chakravarthy J, Ramisetty N, Pimpalnerkar A et al (2005) Surgical repair of complete proximal hamstring tendon ruptures in water skiers and bull riders: a report of four cases and review of the literature. Br J Sports Med 39:569-572

9. Cross MJ, Vandersluis R, Wood D et al (1998) Surgical repair of chronic complete hamstring tendon rupture in the adult patient. Am J Sports Med 26:785-788

10. Jensen IH, Kramhoft M (1994) Distal rupture of the biceps femoris muscle. Scand J Med Sci Sports 4:259-260

11. Lempainen L, Sarimo J, Mattila K et al (2007) Distal tears of the hamstring muscles: review of the literature and our results of surgical treatment. Br J Sports Med 41:80-83

12. Schache AG, Koulouris G, Morris HG et al (2008) Rupture of the conjoint tendon at the proximal muculotendineus junction of the biceps femoris long head: a case report. Knee Surg Sports Traumatol Arthrosc 16:797-802

13. Connell DA, Schneider-Kolsky ME, Hoving JL et al (2004) Longitudinal study comparing sonographic and MRI assessments of acute and healing hamstring injuries. AJR Am J Roentgenol 183:975-984

14. Slavotinek JP, Verrall GM, Fon GT (2002) Hamstring injury in athletes: using MR imaging measurements to compare extent of muscle injury with amount of time lost from competition. AJR Am J Roentgenol 179:1621-1628

15. Servant CT, Jones CB (1998) Displaced avulsion of the ischial apophysis: a hamstring injury requiring internal fixation. $\mathrm{Br} \mathrm{J}$ Sports Med 32:255-257

16. Harris WH (1969) Traumatic arthritis of the hip after dislocation and acetabular fractures: treatment by mold arthroplasty. An endresult study using a new method of result evaluation. J Bone Joint Surg Am 51:737-755

17. Haddad RJ, Cook SD, Brinker MR (1990) A comparison of three varieties of noncemented porous-coated hip replacement. J Bone Joint Surg 72:2-8

18. Clark RA (2008) Hamstring injuries: risk assessment and injury prevention. Ann Acad Med 37:341-346 (review)

19. Sarimo J, Lempainen L, Mattila K et al (2008) Complete proximal hamstring avulsions: a series of 41 patients with operative treatment. Am J Sports Med 36:1110-1115

20. Stanton P, Purdham C (1989) Hamstring injuries in sprinting: the role of eccentric exercise. J Orthop Sports Phys Ther 10:343-349

21. Kujala UM, Orava S, Jarvinen M (1997) Hamstring injuries: current trends in treatment and prevention. Sports Med 23:397404

22. Morgan DL (1990) New insights into the behaviour of muscle during active lengthening. Biophys J 57:209-221

23. Gordon AM, Huxley AF, Julian FJ (1966) The variation in isometric tension with sarcomere length in vertebrate muscle fibres. J Physiol 184:170-192

24. Heiser TM, Weber J, Sullivan G et al (1984) Prophylaxis and management of hamstring muscle injuries in intercollegiate football players. Am J Sports Med 12:368-370

25. Coombs R, Garbutt G (2002) Developments in the use of the hamstring/quadriceps ratio for the assessment of muscle balance. J Sports Sci 1:56-62

26. Hernesman SC, Hoch AZ, Vetter CS et al (2003) Foot drop in a marathon runner from chronic complete hamstring tear. Clin $\mathrm{J}$ Sports Med 13:365-368

27. Street CC, Burks RT (2000) Chronic complete hamstring avulsion causing foot drop: a case report. Am J Sports Med 28:574576

28. Sallay PI, Friedman RL, Coogan PG et al (1996) Hamstring muscle injuries among water skiers: functional outcome and prevention. Am J Sports Med 24:130-136

29. Blasier RB, Morawa LG (1990) Complete rupture of the hamstring origin from a water skiing injury. Am J Sports Med 18:435-437

30. Kurosawa H, Nakasita K, Nakasita H et al (1996) Complete avulsion of the hamstring tendons from the ischial tuberosity: a report of two cases sustained in judo. Br J Sports Med 30:72-74

31. Thomsen NO, Jensen TT (1999) Late repair of rupture of the hamstring tendons from the ischial tuberosity: a case report. Acta Orthop Scand 70:89-91 